\title{
Amyands Hernia: Report of Two Gases
}

\section{Suman Kharkwal, Sameer, Arindam Mukherjee}

From the Department of General Surgery, ESI Postgraduate Institute of

Medical Sciences and Research, New Delhi-1 10015, India.

\begin{abstract}
:
Amyand's hernia, defined as an inguinal hernia with appendix as the content of hernial sac, is a exceedingly rare disease, reported in $1 \%$ of cases of inguinal hernia repair. The appendix can be normal or inflamed and acute appendicitis is seen in $0.13 \%$ of cases. We hereby report two cases of Amyands hernia which were treated at ESI hospital PGIMSR, Delhi highlighting the fact that rather than simply being an anatomical curiosity, Amyands hernias require individualized attention to decide how to manage both the appendix and the hernia. First case was admitted in emergency as strangulated hernia. Inflamed appendix was noted intraoperatively as hernial content for which appendectomy and herniotomy was done. Our second case was worked up as routine case of right congenital hernia and after seeing the content of hernia sac as appendix, appendix was pushed back and herniotomy was done.
\end{abstract}

Key words: Inguinal Hernia, Appendix, Appendicitis, Herniorrhaphy, Appendectomy.

\section{Introduction}

Amyand's hernia is a rare entity in which the content of hernia sac is appendix, with or without inflammation. The incidence of Amyands hernia is approximately $1 \%$ of all inguinal hernias [1]. It was first reported by Claudius Amyand (16601740), a French surgeon working at St George's and Westminster hospitals in London. He performed the first successful appendectomy in 1735, on an 11 -year-old boy who presented with an inflamed, perforated appendix in his inguinal hernia. The case was published in the Philosophical Transactions of the Royal Society of London [2]. We hereby report two cases of Amyands hernia, both of paediatric age group, operated upon in the department of surgery at ESI Hospital PGIMSR, in the period 2009 to 2012.

\section{Case Reports}

\section{Case 1}

A 3 year old child presented to surgical causality with complains of painful non reducible swelling in the right groin. Patient was a known case of congenital heart disease (severe aortic stenosis with mild to moderate pulmonary stenosis). His general examination was normal, cardiovascular examination revealed features of aortic stenosis.

\section{Corresponding Author: Dr. Suman Kharkwal}

Email: drsumankharkwal@gmail.com

Received: May 12,2014 | Accepted: June 30, 2014 | Published Online: July 30, 2014

This is an Open Access article distributed under the terms of the Creative Commons Attribution License (creativecommons.org/licenses/by/3.0)

Conflict of interest: None declared | Source of funding: Nil | DOl: http://dx.doi.org/10.17659/01.2014.0069 
His abdomen was soft, non-distended, local examination revealed a tender swelling in right inguinal region with absent cough impulse. A diagnosis of strangulated right inguinal hernia was made and patient was planned for emergency surgery with high risk consent. His routine investigations were essentially normal. Patient was taken up for emergency surgery. Intraoperative findings were of a large hernial sac containing caecum and inflamed appendix. Appendectomy and herniotomy was done [Fig.1]. Patient did well in postoperative period and was discharged on $4^{\text {th }}$ postoperative day.

\section{Case 2}

An 8 year old boy presented in surgical OPD with a large, reducible right inguinal swelling which was noticed 3 years back. His general and systemic examination was normal. Routine laboratory investigations were done and were in normal limits. A diagnosis of right inguinal hernia was made and the case was posted in routine list. Intraoperative findings were of large hernia sac containing caecum and appendix. The appendix was not inflamed and therefore appendix and caecum were reduced back into peritoneal cavity and herniotomy was done [Fig.2]. Postoperative period was uneventful and the child was discharged on second postoperative day.

\section{Follow up}

Both patients were followed up for 1 year. There was no surgical site infection and no recurrence was noticed.

\section{Discussion}

Amyands hernia is a rare clinical entity accounting for $1 \%$ of all inguinal hernias. It is difficult to diagnose this condition pre-operatively and in majority of cases it is an intraoperative finding.

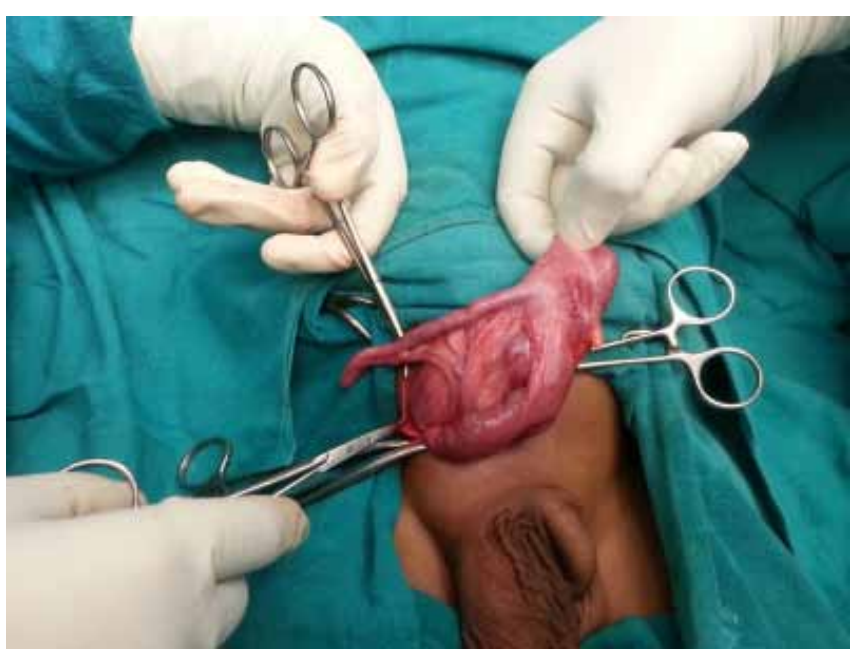

Fig.1: Intraoperative photograph of appendix inside the hernial sac.

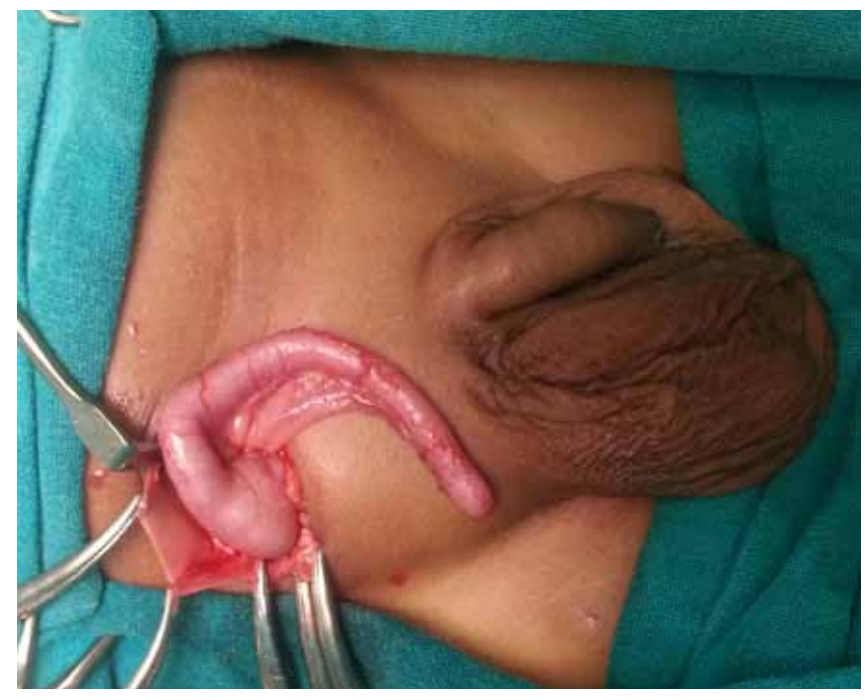

Fig.2: Intraoperative photograph showing appendix and caecum as hernial content.

Acute appendicitis within an inguinal hernia accounts for $0.1 \%$ of all cases $[2,3]$. Inflammation of the appendix is attributed to external compression of the appendix at the neck of the hernia. Losanoff and Basson created a classification system to identify and treat Amyand's hernias (Table 1) [4,5]. Type 1 hernia has a normal appendix in an inguinal hernia, which is managed with a reduction and mesh 
repair. Type 2 to 4 have acute appendicitis within an inguinal hernia sac. Type 2 has an inflamed nonperforated appendix. Type 3 has a perforated appendix and type 4 is complicated with intraabdominal pathology. The inflammatory status of the vermiform appendix determines the surgical approach and the type of hernia repair. All surgeons agree that if appendicitis exists, the repair of the hernia should be performed with Bassini or Shouldice techniques, without making use of synthetic meshes or plugs within the defect $[2,6,7]$ due to the high risk of suppuration of such materials. In the case of a normal appendix, incidentally found within the hernia sac, the performance of a prophylactic appendectomy along with the hernia repair is not favored by many authors [8,9]. Appendectomy adds the risk of infection to an otherwise clean procedure. Most authors recommend reduction of the appendix and mesh hernioplasty if appendix is normal and appendectomy followed by Bassini or Shouldice hernia repair if an inflamed appendix is found $[3,9]$. Coming to our cases, our first case was Type 2, with appendix being inflamed and we performed appendectomy and herniotomy. The second case was Type 1 Amyands hernia, the appendix was reduced back and herniotomy was done. Posterior wall repair was not done in view of both patients belonging to pediatric age group. The patients were followed up for one year, there was no incidence of surgical site infection in immediate post-operative period and no recurrence was noted later.

\section{Conclusion}

Hernia is one of the most common operations done by general surgeons, however it is known to throw challenges even for experienced surgeons. Amyands hernia is rare clinical entity which is difficult to diagnose preoperatively. In each case of Amyands hernia, the treatment has to be individualized depending upon the findings and our case report highlights the same,

\section{References}

1. Ballas K, Kontoulis T, Skouras C, Triantafyllou A, Symeonidis N, Pavlidis $T$, et al. Unusual findings in inguinal hernia surgery: Report of 6 rare cases. Hippokratia 2009;13(3):169-171.

2. Amyand $C$. Of an inguinal rupture, with a pin in the appendix caeci, incrusted with stone; and some observations on wounds in the guts. Philos Trans R Soc London 1736;39:329-336.

3. Livaditi E, Mavridis G, Christopoulos-Geroulanos G. Amyand's hernia in premature neonates: report of two cases. Hernia 2007;1 1(6):547549.

4. Losanoff JE, Basson MD. Amyand hernia: what lies beneath-a proposed classification scheme to determine management. Am Surg 2007;73(12):1 288-1290.

5. Losanoff JE, Basson MD. Amyand hernia: a classification to improve management. Hernia 2008; 1 2(3):325-326.

6. Llullaku SS, Hyseni HS, Kelmendi BZ, Jashari HJ, Hasani AS. A pin in appendix within Amyand's hernia in a six-years old boy: case report and review of literature. World J Emerg Surg 2010;5:14.

7. Sharma H, Gupta A, Shekhawat NS, Memon B, Memon MA. Amyand's hernia: a report of 18 consecutive patients over a 15-year period. Hernia 2007;1 1(1):31-35.

8. D'Alia C, Lo Schiavo MG, Tonante A, Taranto F, Gagliano E, Bonanno L, et al. Amyand's hernia: case report and review of the literature. Hernia 2003;7(2):89-91.

9. Salemis NS, Nisotakis K, Nazos K, Savrinou P, Tsohataridis E. Perforated appendix and periappendicular abscess within an inguinal hernia. Hernia 2006;10(6):528-530. 